\title{
A educação e o desenvolvimento na agenda europeia do crescimento: uma reformulação desde as organizações da sociedade civil
}

\author{
Education and development through the \\ European agenda concerning growth: a reformulation \\ departing from the civil society organizations
}

\author{
Manuel Gonçalves Barbosa ${ }^{1 *}$
}

\begin{abstract}
Resumo
As agendas do crescimento estão de regresso à região europeia e todo o discurso acerca da educação e do desenvolvimento já está a sofrer o seu efeito. A eventualidade de uma degradação desse discurso é uma ameaça para a educação que se alia à promoção de um desenvolvimento verdadeiramente humano e com preocupações ecológicas e, por isso, equacionamos, neste artigo, a sua ressignificação desde baixo, ou seja, desde as organizações da sociedade civil que reagem, no dia a dia e em diversos fóruns, contra a redução da educação e do desenvolvimento às perspetivas mais estreitas do crescimento econômico e da acumulação de riqueza para fazer face ao desemprego e às dívidas públicas, que hoje monopolizam as atenções e as preocupações dos meios políticos ocidentais.
\end{abstract}

Palavras-chave: educação; desenvolvimento; crescimento; sociedade civil

\begin{abstract}
The agendas of growth are back to the european region and the whole speech about education and development is already suffering its effects. The possibility of a degradation of that speech is a threat to education that allies to the promotion of a truly human development and ecological concerns and, therefore, we analize in this article its redefinition from below, ie, from the organizations of civil society that react in the everyday life and in several fora, against the reduction of education and development to the closer perspectives of economic growth and accumulation of wealth to tackle unemployment and public debts that nowadays monopolize the attention and concerns of western political circles.
\end{abstract}

Keywords: education, development, growth, civil society

* Professor Doutor do Instituto de Educação da Universidade do Minho-Portugal

Ano 13 • n. 1 • jan./jun. 2013 - 239 


\section{Introdução}

O crescimento está de regresso às agendas políticas do nosso tempo e é mesmo uma obsessão em determinados países da OCDE, muito particularmente nos Estados-membros da União Europeia. Aqui, a palavra fetiche, ou a nova figura do sagrado, é o crescimento econômico, único capaz de resgatar o ideal de justiça social, hoje cada vez mais desacreditado junto da grandes massas de empobrecidos e excluídos, quer do emprego, quer dos benefícios do Estado-providência.

A hora parece ter chegado para tudo subordinar às perspetivas do crescimento, e isso tanto do lado da educação quanto do desenvolvimento. Na verdade, a educação e o desenvolvimento, enquanto parceiros de viagem, nunca deixaram de sintonizar com as necessidades do crescimento, pelo menos desde o fim do segundo grande conflito mundial, mas hoje, face à estagnação e à recessão de várias economias avançadas, nomeadamente na região europeia, a palavra de ordem, para a educação e o desenvolvimento, é manifestamente o crescimento.

O relançamento do crescimento econômico, sendo incontornável para certos países, não deixa de causar perplexidades pelo atrofiamento que pode impor em termos de desenvolvimento e, correlativamente, da educação enquanto estratégia-chave do seu cumprimento. De facto, o estreitamento das conceções de educação e desenvolvimento já se está a verificar na região europeia e importa questioná-lo desde já para não nos lamentarmos, mais tarde, que se avançou desmesuradamente nesse reducionismo.

Ao mesmo tempo, importa equacionar se é chegada a hora de ressignificar a educação e o desenvolvimento tendo em conta o superior interesse da pessoa humana nas circunstâncias presentes e se essa mudança de narrativa pode ser protagonizada pela sociedade civil, nomeadamente por intermédio das suas organizações mais emblemáticas e combativas no espaço público: as associações cívicas e os movimentos sociais. 
O propósito é, portanto, este: partir de uma análise da subordinação da educação e do desenvolvimento às perspetivas do crescimento econômico na região europeia e averiguar, com sentido hipotético e prospectivo, se uma nova narrativa de educação e desenvolvimento pode ser patrocinada pela sociedade civil sobre a base de uma ampla consideração dos desafios que hoje se colocam à pessoa humana, quer em termos de vida em comum nas sociedades democráticas pluralistas, quer naquilo que tem a ver com a defesa e a proteção das condições de permanência e viabilidade ecológica dessa vida comunitária.

\section{0 retorno do feiticismo do crescimento: a educação e o de- senvolvimento em tempos de crise}

Como meta do desenvolvimento e tarefa subsidiária da educação, o crescimento econômico não é um paradigma recente. O seu prestígio já vem de longe. Remonta, pelo menos, aos anos que imediatamente se seguiram à Segunda Guerra Mundial e às apostas que então se fizeram na industrialização e na modernização. Abrangendo no mesmo arco a educação e o desenvolvimento, esse paradigma afirmava claramente os princípios da racionalidade econômica mais estrita e desconsiderava, por esse facto, outras variáveis que não as relativas ao aumento do produto interno bruto. A grande paixão era o crescimento e este, na sua dimensão económica, media-se como progressão do PIB, quer dizer, " a progressão do volume de todas as produções de bens e serviços que se vendem, ou com preço monetário, produzidos pelo trabalho remunerado "(LATOUCHE, 2011, p. 48-49).

Os círculos internacionais ligados à promoção do desenvolvimento, nutridos pela experiência de três décadas das Nações Unidas para o Desenvolvimento, e não contentes com essa visão excessivamente focalizada na prosperidade econômica, acabam por protagonizar, no início da década de 1990, uma inversão de perspectivas: desde o palco mundial das Nações Unidas e do seu Programa para o Desenvolvimento (PNUD) passam a defender e a inscrever, em sucessivos relatórios, que o paradigma orientador 
tem que ser outro; não mais o crescimento pelo crescimento, ou a "fixação economicista no primado do rendimento e da riqueza" (Sen, 2003, p. 35), mas a efetiva melhoria da qualidade de vida das pessoas, agora medida em termos de liberdade, democracia, segurança, igualdade de gênero, participação, direitos humanos e proteção do meio ambiente.

A partir dessa inversão paradigmática, e até muito recentemente, uma coisa parecia certa: o desenvolvimento, assessorado pela educação, elege as pessoas como centro e pensa-se, no âmbito de programas e projetos comunitários, de maneira integral e multidimensional por forma a abranger, em todo o lado, os componentes essenciais de uma vida decente e digna.

Aquilo que parecia certo e um dado adquirido, quer no nível das ações e da assunção de medidas, quer no nível da retórica e das intenções, deixou de o ser a partir de 2008 aproximadamente, altura em que se começa a assistir a um agravamento e a uma deterioração da situação econômico-financeira de importantes economias avançadas do Ocidente, designadamente, e em grande medida, das economias da região europeia. Subitamente, e num clima de grande preocupação quanto ao futuro do Estado social e de sustentação das sociedades de bem-estar material, dá-se um volte-face nas perspetivas da educação e do desenvolvimento e um regresso ao passado. Um regresso que significou a retomada do "velho" paradigma do crescimento económico enquanto modelo diretor e imaginário orientador quer da educação quer do desenvolvimento.

O volte-face paradigmático, na região europeia, é bem visível em vários documentos da Comissão Europeia, mas há um que é exemplar na cronologia e na terminologia: a "Estratégia Europa 2020", dado a lume em março de 2010 e ainda nesse ano rubricado pelo Conselho e o Parlamento europeus. O objetivo da Estratégia, no meio de tantas ansiedades e incertezas quanto ao futuro da União, é claro e não deixa dúvidas: "Trata-se de uma agenda para todos os Estados-Membros, tendo em conta as diferentes necessidades, os diferentes pontos de partida e especificidades nacionais, a fim de promover o crescimento de todos" 
(COMISSÃO EUROPEIA, 2010, p. 12). A prioridade é manifestamente o crescimento, agora ressignificado como "crescimento inteligente", já que se trata de relançar e desenvolver "uma economia baseada no conhecimento e na inovação" (2010, p. 5). O que se quer é "uma União da inovação... para assegurar que as ideias inovadoras são transformadas em produtos e serviços que criam crescimento e postos de trabalho" (2010, p. 6). Visa-se a estratégias de retorno ao crescimento e isso exige instrumentar a educação, sempre de mãos dadas com o desenvolvimento, no sentido desse crescimento:

Um crescimento inteligente significa reforçar o conhecimento e a inovação, enquanto fatores determinantes do nosso crescimento futuro. Para tal é necessário melhorar a qualidade da nossa educação, reforçar o desempenho da nossa investigação. Promover a inovação e a transferência de conhecimentos em toda a União, tirar plenamente partido das tecnologias da informação e da comunicação e assegurar a transformação das ideias inovadoras em novos produtos e serviços que criam crescimento e emprego de qualidade e que ajudam a enfrentar os desafios societais que se colocam a nível europeu e mundial (2010, p. 14).

O crescimento é o eixo articulador de toda a Estratégia e consubstancia-se, in fine, em crescimento essencialmente econômico, ainda que se diga que deve ser sustentável e inclusivo além de inteligente.

Com essa estratégia, e pelo período de uma década, a União dos vinte e sete recoloca a educação e o desenvolvimento na linha direta do crescimento e prepara o terreno para uma mudança de fundo no que concerne à missão das instituições educativas, nomeadamente as instituições de ensino médio e universitário. Aqui e ali, a mudança já é notória e verifica-se que passa, fundamentalmente, pelo recentramento da escola na norma da profissionalização e da empregabilidade. A escola, objeto de culto econômico e protagonista de uma nova narrativa, é pouco a pouco reordenada e reorientada em função da finalidade profissional dos estudos. Na prática, isso está a passar por uma definição mais uti- 
litária dos conteúdos de formação, com uma sobrevalorização das áreas científicas e técnicas; pela seleção dos estudantes através de dispositivos de orientação e acompanhamento visando à inserção no mercado de trabalho; pela inculcação do espírito de empresa e pela centração economicista nas virtudes do empreendedorismo; pela multiplicação dos estágios em contexto laboral e pela definição estritamente profissional de livretes de competências como passaportes para o emprego.

Verifica-se, neste espaço europeu de novo obcecado com o crescimento econômico, que a escola está em vias de reorganização curricular e que essa reorganização visa tão somente à sua adequação aos imperativos desse crescimento através da construção de novas funcionalidades e de novas subjetividades. Por um lado, acentua-se a visão mercantil dos estudos e a relação instrumental com a escolaridade: "Trata-se menos de aprender do que gerir o seu percurso em função de imperativos econômicos" (LAVAL, VERGNE, CLÉMENT, DREUX, 2011, p. 191). Por outro, opera-se uma relativização da missão de transmissão de saberes em ordem a favorecer, através da escola, "a fabricação de uma subjetividade mercantil" (2011, p. 184) e o acesso às competências congruentes com os objetivos do crescimento.

Os percursos escolares, a essa luz, já não são referidos a exigências de verdade e de construção conceptual, ou sequer à formação de cidadãos lúcidos e críticos em relação à sua situação, mas a uma racionalidade que invade todas as esferas da existência humana em sociedade: a racionalidade econômica.

Sob os auspícios dessa racionalidade, as instituições de educação e formação transformam-se num campo fértil de mercadorização de serviços ao cliente e assumem-se cada vez mais como lugares de acumulação de capital. Repentinamente, desinteressam-se da formação de cidadãos, ou de pessoas aptas para viverem em sociedade, capazes de escolher, julgar e controlar os seus representantes, e passam a investir em capital humano, ou seja, na produção de subjetividades acomodadas às exigências do "crescimento inteligente", num mundo de guerras econômicas e financeiras à escala global. 
Num contexto como este, e nas condições particulares da região europeia, a tentação é centrar a ação educativa no desenvolvimento do potencial econômico dos indivíduos e transformar as instituições com esse mandato em campo de treino, ora da empregabilidade, ora da reciclagem permanente. Como os desafios do crescimento passam hoje pelo investimento no conhecimento, ou seja, pelo capital imaterial, esse mandato deve produzir o novo homem conforme a economia do conhecimento, hoje rebatizada de "inteligente" pela Comissão Europeia (2010, p. 5).

A grande "casa" europeia, assediada pela guerra econômica global e em risco de ter que rever em baixa as expectativas em relação ao Estado social, aposta decisivamente no crescimento do produto interno bruto e, assim, contra a retórica que tem defendido, corre aceleradamente para a maximização do valor instrumental das pessoas, fazendo delas, nesta época de crise, meros recursos para as empresas. A crise está a servir de pretexto a essa visão restritiva das pessoas, quando as pessoas, devidamente consideradas, não são apenas esses recursos: "Os seres humanos não são meros meios de produção" (SEN, 2003, p. 302). São mais que capital humano ao serviço da economia e do crescimento econômico. Se é verdade que precisamos de pessoas preparadas para as atividades produtivas, ergo para o mundo do trabalho, e se não podemos ignorar que o crescimento, dentro de limites sustentáveis, pode ser imprescindível para o desenvolvimento humano, também é certo que as pessoas são fins em si mesmas e não meros utensílios da economia.

De resto, é preciso sublinhar que "não há vínculo automático entre crescimento e desenvolvimento" (PEDRAJAS Y JORDÁN, 2009, p. 225). A assimilação do crescimento a uma elevação do bem-estar e, por maioria de razão, à felicidade, é, segundo a expressão de Jean Baudrillard, "um extraordinário bluff coletivo... uma operação de magia branca" (1970, p. 42). O elevado crescimento econômico não se traduz necessariamente no bem-estar de todos:

Não é pelo facto do crescimento aumentar os rendimentos globais e melhorar a situação média em termos monetá- 
rios que reduz as desigualdades de riqueza. Como vem a ser mostrado, desde 2004, pela Comissão mundial sobre a dimensão social da globalização, muitas riquezas são criadas, porém, não são de nenhum proveito para muitas pessoas e muitos países (LAVILLE, 2010, p. 169).

Sem medidas políticas concretas, muitas vezes ao arrepio dos interesses mais firmemente estabelecidos, não há meio de traduzir o progresso econômico em verdadeiro progresso humano, respeitador da igual dignidade de todos e do direito que todos têm a "vidas plenas e criativas" (NUSSBAUM, 2012, p. 217) no seio de ambientes viáveis e duráveis, tanto naturais como sociais.

$\mathrm{O}$ regresso do feiticismo do crescimento econômico à região europeia, tanto mais aclamado quanto se acentuam, no presente momento, os efeitos negativos da crise das dívidas soberanas, pode fazer perder de vista esse horizonte mais amplo do desenvolvimento e, por extensão, da educação como vetor estratégico do seu cumprimento, quer através de instituições de ensino e aprendizagem vocacionadas para o efeito, quer através da própria sociedade civil, pois, como é justo reconhecer, as suas organizações também são protagonistas de educação e desenvolvimento. A promoção do desenvolvimento é uma responsabilidade partilhada e a sociedade civil, com o seu potencial educativo, também pode dar um interessante contributo nesse sentido.

\section{Educação, sociedade civil e desenvolvimento}

O desenvolvimento que se revela cada vez mais necessário está fortemente condicionado por exigências e aspirações que vão além do mero crescimento econômico. O crescimento econômico, "não obstante fazer parte de uma política pública sensata, não é mais que uma parte e um instrumento dessa política. As pessoas é que importam em última instância" (NUSSBAUM, 2012, p. 217). A finalidade do desenvolvimento, tal como a meta de uma boa política nacional e internacional, consiste em dar alento às aspirações das pessoas, as quais vão além da satisfação de necessidades básicas. "As pessoas têm, sem dúvida, necessidades, 
porém, também têm valores...Visualizar as pessoas unicamente em função das suas necessidades poderia transmitir uma visão bastante limitada da humanidade" (SEN, 2007, p. 54).

A perspetiva do desenvolvimento que não se deixa ofuscar e seduzir pelo fetiche do crescimento pensa acima de tudo no bem-estar das pessoas. É um desenvolvimento das pessoas, para as pessoas e com as pessoas. Se não discute a relevância das variáveis econômicas, e da própria sustentabilidade, na qualificação da vida humana, dado serem essenciais a esse propósito, também não se conforma com a redução do progresso a essas variáveis e, mais do que isso, a uma visão da sustentabilidade estritamente vinculada à satisfação de necessidades, tanto das presentes gerações como das gerações futuras.

Uma nova narrativa de educação e desenvolvimento, quer em termos ambientais, quer em termos sociais, tem certamente a ganhar com essa largura de perspectivas e, eventualmente, com o contributo das organizações da sociedade civil. Por que sociedade civil? Só por que está na moda desde alguns anos a esta parte, ou porque seria um desperdício não aproveitar a sua real implicação em questões de educação e desenvolvimento?

A sociedade civil, não obstante a confusão e a ambiguidade a propósito do seu significado, precisa de ser convocada quando está em causa a ressignificação da educação e do desenvolvimento, pois, como se vai reconhecendo cada vez mais, a sociedade civil é um importante agente de educação e desenvolvimento. Concretamente, de que estamos falando quando nos referimos à "sociedade civil"?

A sociedade civil é um significante de pluralidade e isso quer dizer, em condições de crescente diferenciação social, que a sociedade civil se estrutura como conjunto diversificado, e por vezes contraditório, de grupos, movimentos e associações. O âmbito da sociedade civil, mais ou menos dilatado conforme os quadros políticos de referência e as práticas institucionalizadas dos seus atores, configura tanto a solidariedade e a cooperação como a disparidade e a fragmentação. A sociedade civil é "o reino da fragmentação e da luta, mas também de solidariedades concretas 
e autênticas" (WALZER, 1998, p. 16). Nas suas esferas "andam de mãos dadas a racionalidade estratégica e a comunicativa, a competição de interesses e a cooperação, o individualismo egoísta e a solidariedade" (Cortina, 1998, p. 192). Se, por um lado, dá aos indivíduos a oportunidade de cooperarem em defesa de interesses comuns, também os coloca em rota de colisão quando autoriza a prossecução de interesses divergentes e contraditórios tanto nas esferas públicas como privadas.

A sociedade civil, apesar da imprecisão que rodeia o seu significado, é um valor bem cotado nas estruturas conceptuais do pensamento político contemporâneo. Renasceu em grande escala nas décadas de 1980 e 1990 e pode dizer-se, sem grandes exageros, que se tornou a vedeta do pensamento em torno da sociedade e da política. Há certamente um largo consenso acerca da sua importância, mas há igualmente um crescente desacordo acerca do seu sentido exato. "Há mesmo sinais, diz-nos J. Keane (2001, p. 49), de que os sentidos da expressão 'sociedade civil' estão a multiplicar-se a um ponto tal que, como uma frase publicitária que chama a atenção, ela se arrisca a implodir devido ao excesso de uso".

A linguagem em torno da sociedade civil é cada vez mais confusa, tem diferentes regras de gramática e, o que é pior, remete frequentemente para vocabulários contraditórios. Por isso, como reconhece Olvera, "falar de 'uma' sociedade civil... é problemático" (2003, p. 412), pois a expressão faz referência, aqui e agora, a uma grande variedade de associações, grupos, instituições, atores, movimentos, todos marcados por uma grande diversidade de objetivos e pontos de vista acerca do que deve ser uma sociedade 'boa'. Seja como for, algumas consensualidades se têm construído em torno dessa matéria: longe de corresponder a uma visão abrangente e totalizadora, onde se incluem as esferas política , econômica e social, tanto no que toca às normas como às instituições e aos atores, a sociedade civil afirma-se hoje, essencialmente, como uma realidade formada por redes de agregação voluntária, sejam movimentos sociais, sejam sobretudo associações. 
Essas consensualidades, ou convergências, colocam a sociedade civil entre o indivíduo e o Estado (REQUENA, 2008, p. 33) e distinguem-na, na maioria dos casos, da esfera econômica e do mercado. Ou seja, o que predomina hoje é uma visão associativa e auto-organizativa da sociedade civil, tanto à margem do mercado como do Estado, bem na linha da valorização tocquevilliana da associação espontânea dos cidadãos. Isso mesmo é reconhecido por um especialista na matéria, fazendo a síntese das ideias comumente aceites:

Originariamente, a expressão 'sociedade civil' refere-se a um tipo de sociedade, e inclui tanto o estado como os mercados e o tecido associativo. Com o tempo, deu-se um deslocamento semântico, mediante o qual a sociedade civil passou a significar 'o que não é estado' (mercados e associações) ou a reduzir-se a associações. Hoje em dia, é muito frequente que na comunidade académica, política e mediática se use a sociedade civil como sinónimo de associações ou tecido associativo (PÉREZ-DIAS, 2008, p. 222).

Os usos sociais da noção de sociedade civil são plurais e não se pode esconder que há apropriações ideológicas dessa noção. A promoção mediática da sociedade civil nem sempre se articula com um projeto de emancipação coletiva e, portanto, com uma aposta em novas ideias e novos valores. Ainda assim, é importante reconhecer o seu protagonismo na educação e na formação das pessoas e o apoio que pode dar, neste tempo de novos desafios sociais e ambientais, à promoção de uma nova noção de desenvolvimento.

A ação educativa da sociedade civil, mais além das instituições formais de ensino, é uma evidência, mesmo que não se vá tão longe quanto Walzer (2010, p. 197). É um facto que a sociedade civil contribui enormemente para nos tornarmos homens e mulheres sociáveis e comunitários. Nas organizações da sociedade civil aprendemos a viver juntos, a respeitar regras e a desenvolver os nossos talentos de seres humanos. "Todas as associações desenvolvem as suas próprias disposições normativas 
e fazem a promoção de valores e comportamentos que julgam os mais adequados" (PIROTTE, 2007, p. 54).

Há todo um potencial educativo a explorar nas arenas da sociedade civil, primeiro pelo trabalho hermenêutico da reflexão pedagógica e, depois, pelas iniciativas da ação política, visando a esses incentivos e recompensas a todas as organizações que se comprometam com os objetivos do desenvolvimento humano. Com efeito, não basta assinalar que as organizações da sociedade civil são uma peça-chave na promoção do desenvolvimento, como de facto vem acontecendo desde os anos 1980 e 1990, e isso tanto pela Comissão Europeia (2001) como pela Unesco (2005), ou pelo FMI e o Banco Mundial, na sequência da adoção do paradigma de desenvolvimento participativo como novo referente da ajuda ao desenvolvimento (OCDE, 1995). Se, nas três décadas que se seguiram à Segunda Guerra Mundial, a noção de sociedade civil esteve ausente da reflexão sobre os caminhos do desenvolvimento, já por volta dos anos 1990 a mesma noção torna-se uma peça verdadeiramente central, para não dizer indispensável, das políticas de desenvolvimento tal como foram concebidas e orquestradas pelas agências internacionais.

A sociedade civil, libertando-se do poder sufocante do Estado e da sua tendência para castrar as suas iniciativas, ainda que colaborando com ele nas parcerias do desenvolvimento e da educação para o desenvolvimento, designadamente através de associações e ONG's, começa a ter o reconhecimento que merece, não obstante os perigos de instrumentalização a que está sujeita, quer por parte dos agentes do Estado, quer por parte do mercado.

A sociedade civil não é a única depositária do bem público (OTAYEK, 2007, p. 147) e nem sequer é um poço de virtudes. "Não devemos esperar tudo de todo o tipo de associações da sociedade civil" (WARREN, 2004, p. 89). Ainda assim, e na atualidade, face à necessidade de alavancar, desde as suas esferas, um renovado sentido humanista da educação e do progresso, ou seja, do desenvolvimento que dá centralidade aos valores mais apreciados pelas pessoas, importa resgatar e valorizar o seu potencial, 
nomeadamente aquele que "pode chegar a modificar profundamente a vida pessoal mediante a transformação de certos estilos de vida e pautas de comportamento" (TEJERINA, 2005, p. 89).

Não há que esperar revoluções extraordinárias das organizações da sociedade civil em termos propositivos e especialmente educativos. Porém, sempre podem contribuir com novas ideias, novos valores e novas práticas quando se trata de encarar de frente o desenho e a materialização de uma nova narrativa de educação e desenvolvimento. Ou seja, quando se afigura premente, tanto em palavras como em atos, a ressignificação da educação e do desenvolvimento mais além do feiticismo do crescimento, da criação de riqueza, do produtivismo e da acumulação de capital.

\section{Mais além do crescimento: ressignificando a educação e o desenvolvimento a partir da sociedade civil}

A ressignificação da educação e do desenvolvimento não é uma tarefa exclusiva da sociedade civil e mal estaríamos se não contássemos, mais cedo ou mais tarde, com o protagonismo do Estado. Os poderes públicos têm sempre o seu lugar, quanto mais não seja para tomar medidas legislativas e definir enquadramentos normativos. O desejável é uma ação conjunta de Estado e sociedade civil, porém, enquanto isso não acontece, um impulso pode ser dado a essa ressignificação desde baixo, ou seja, desde as estruturas da sociedade civil que se empenham, nas diversas arenas do espaço público, em abrir fissuras no pensamento dominante e em marcar novas direcionalidades à educação e ao desenvolvimento.

A educação e o desenvolvimento precisam do apoio da sociedade civil para se libertarem do espartilho do economicismo e isso passa, hoje em dia, por interpretar as aspirações das pessoas num quadro tão diverso e tão complexo de desafios como a revitalização da vida em comum nas sociedades democráticas pluralistas e a preservação dos recursos e das condições ambientais essenciais a uma vida digna, tanto das gerações presentes como das futuras. 
A ressignificação da educação e do desenvolvimento, a ser realista e oportuna, assume para si esses desafios e organiza, através das organizações mais combativas da sociedade civil, uma resposta a esse desafios, tanto nas palavras como nos atos. De que modo isso poderia ser feito?

Antes de mais, insistindo na necessidade de uma socialização na diversidade e de uma rutura com os mecanismos da divisão e da separação do espaço urbano em ajuntamentos seletivos, enclaves étnicos, zonas proibidas e fechadas conforme a cultura, a religião e a própria classe social. A socialização na diversidade ajudaria a combater esse "separatismo urbano" (BAUMAN, 2009, p. 38) e teria por ambição, nas áreas de maior tendência à homogeneização, a sistemática exposição de toda a gente a toda a gente a fim de as pessoas se tornarem menos estranhas uma das outras, menos insensíveis e também menos insolidárias. Uma socialização na diversidade, patrocinada e estimulada pela sociedade civil, pelos seus movimentos e associações, ajudaria a vencer o medo dos estranhos, a dissipar os temores ao desconhecido e a adquirir, num contexto de maior proximidade, as competências sociais e relacionais que a vida em comum exige ou solicita, seja para realizar iniciativas e projetos de interesse geral, seja para conviver na sociedade multicultural.

O desenho e a materialização de uma nova narrativa de educação e desenvolvimento, partindo da sociedade civil e tomando como referência os desafios mais urgentes do presente, insiste nessa renovada modalidade de socialização, quanto mais não seja para reaprendermos a viver juntos, e dá particular atenção a duas importantes figuras de cidadania que precisamos de reativar: a cidadania democrática, por um lado, e a cidadania ecológica, por outro.

A importância da cidadania democrática justifica-se por dois motivos: em primeiro lugar, porque é necessária ao envolvimento ativo dos cidadãos nas novas formas de governo dos assuntos comuns, hoje mais descentralizadas e mais próximas das coletividades. Depois, e em segundo lugar, porque não há meio de a evitar quando se coloca a questão da reconstrução da democra- 
cia como projeto de vida em comum, baseado na prossecução de valores como a liberdade, a igualdade e a solidariedade, hoje em "estado de moratória" até que a crise desapareça do horizonte, em particular nas economias da região europeia.

A primeira das razões tem a ver com a implicação dos cidadãos em novas modalidades de governo resultantes da manifesta impossibilidade de os Estados corresponderem, sozinhos, às crescentes demandas sociais e de não serem capazes de afrontar, com os seus recursos, os desafios emergentes nas áreas da gestão dos territórios, como, por exemplo, as cidades. Uma dessas novas formas de governo é a "governança democrática", a qual é hoje patrocinada, em solo europeu, pela Comissão Europeia. Essa comissão tem vindo a promover o governo como modo de governar baseado na horizontalidade e na concertação e isso tem que ver, não apenas com a prática de um governo supranacional que tem de articular os interesses de diferentes governos dos Estados-nação, mas também com a necessidade de incorporar os governos regionais, locais e a própria sociedade civil na construção da Europa. De acordo com o Livro Branco sobre Governança Europeia, elaborado pela Comissão Europeia em 2001, o conceito de governo abrange cinco princípios básicos: abertura, participação, responsabilidade, eficácia e coerência. Os princípios, segundo a filosofia desse documento, têm em vista fortalecer a relação da UE com a sociedade civil e um maior uso das capacidades dos atores regionais e locais em estabelecer as bases de uma clara definição dos objetivos políticos da UE e centrar os papéis e as responsabilidades de cada instituição. A governança, nesse sentido, associa-se diretamente com uma aposta de governo pela descentralização, a participação cidadã e a colaboração da sociedade civil.

A governança democrática, com esse contributo da Comissão Europeia, é hoje entendida como nova arte de governar os territórios visando a desenvolvimento humano, assente na participação dos cidadãos, no fortalecimento dos valores cívicos, na revalorização da política democrática e na construção coletiva do interesse geral. Como refere Pascual Esteve,

A governança democrática é uma nova forma de gover-

Ano $13 \cdot$ n. $1 \cdot$ jan./jun. $2013-253$ 
nar o território que dá prioridade a dois temas: a articulação e complementaridade de atuações públicas e privadas em projetos de ação com objetivos comuns (projetos em rede) e a responsabilização e envolvimento dos cidadãos em temas de interesse geral (2011, p. 290).

Esses temas relacionam-se com a gestão urbana, os cuidados de saúde ou mesmo a educação. Assim, e desde a sociedade civil, a atribuição de significado relevante à cidadania democrática acaba por ser necessária à dinamização e à sustentação dessa nova forma de governação a que se chama presentemente governança democrática.

A ênfase colocada na cidadania democrática, desde as esferas mais representativas e mais combativas da sociedade civil, justifica-se, em segunda análise, pela urgência de reconstruir, nestes tempos sombrios, a própria democracia como projeto de vida em comum (ROSANVALLON, 2011, p. 393-395) assente nos valores da liberdade, da igualdade e da solidariedade. Da liberdade como potencialidade de fazer aquilo que mais valorizamos na vida (SEN, 2003, p. 71); da igualdade ou da mesma dignidade de todos os seres humanos; e da solidariedade como compromisso cívico em relação à defesa das vítimas do não reconhecimento, da exclusão, da indecência e da humilhação.

Igualmente importante para a vida em comum, e mais ainda para a sua sustentabilidade, é o apoio que a sociedade civil pode dar à cidadania ecológica por intermédio de associações ambientalistas e de organizações não governamentais que se destacam nessa área. Além de cidadãos ativos e participativos nas novas formas de governação, as sociedades, na era dos problemas ambientais globais e da "crise ecológico-planetária" (LIMÓN, 2007, p. 110), também precisam de cidadãos conscientes desses problemas, dessa situação, e dispostos a colocarem o seu grão de areia na empresa coletiva de se conseguir a sustentabilidade ambiental.

Além da reivindicação do direito a um meio ambiente adequado para a saúde e o bem-estar, sempre importante e indispensável, o cidadão ecológico ou ambiental, encorajado pela 
sociedade civil e dela colhendo os bons exemplos, estaria sobretudo preocupado com o bem comum da sustentabilidade, e isso tanto em nível local como global, já que os problemas ambientais atuais, verdadeiramente sérios, não têm barreiras nem fronteiras. Uma cidadania ecológica articulada em torno desse objetivo estaria, segundo Dobson (2010, p. 155), mais centrada nas responsabilidades do que nas prerrogativas ambientais, ou seja, nos direitos. Assim, o que se exigiria ao cidadão ecológico, a esse cidadão que a sociedade civil também ajuda a construir nas suas esferas, é que não comprometa a capacidade de outras gerações, presentes ou futuras, e não só do seu país, de realizarem opções valiosas e de viverem uma vida significativa. Se há uma obrigação para o cidadão, ambiental ou ecológico, essa obrigação só pode ser, diante da defesa da sustentabilidade, a redução dos impactos no ecossistema, e isso enquanto se produz e reproduz a vida diária, seja no domicílio, seja nos lugares públicos. Dessa forma, educar para a cidadania ecológica é educar para assumir responsabilidades não só em relação ao presente mas também em relação ao futuro, é ir além de territórios bem delimitados, como a esfera privada e o próprio país, e é ainda uma ação de conscientização visando ao conhecimento e à mobilização para a defesa dos valores ambientais.

A sociedade civil, através dos seus atores e das suas organizações, não garante, em todo o lado, esse tipo de educação, como aliás não assegura, a priori, os incentivos à cidadania democrática. Ainda assim, sabemos que ajuda a enfrentar os desafios ambientais atuais e isso já é reconhecido, inclusive, no Documento Final da Unesco sobre a Década da Educação para o Desenvolvimento Sustentável quando é cometido à sociedade civil a tarefa de promover valores, como: "respeito e cuidado pela grande comunidade da vida, que inclui proteção e restauração dos ecossistemas da Terra", ou ainda, e tendo em conta esses valores, "estimular a sensibilização dos cidadãos, organizar atividades de promoção, campanhas e grupos de pressão" (2005, p. 43 e 70).

A ressignificação da educação e do desenvolvimento, abrangendo no mesmo arco as palavras e os atos, tem um im- 
portante aliado nas organizações da sociedade civil que investem na revitalização da vida em comum e na preservação das condições ambientais essenciais a uma vida decente e digna, tanto das gerações presentes como das futuras. Se a motivação para uma ressignificação da educação e do desenvolvimento mais além do crescimento não pode vir, na região europeia, da esfera dos poderes públicos, dada a sua obsessão pela melhoria dos indicadores económicos, talvez seja adequado olhar noutra direção e depositar as nossas esperanças nas organizações que, desde baixo, introduzem novas práticas e novos vocabulários acerca da educação e do desenvolvimento nestes tempos de negação de direitos e de frustração das mais profundas aspirações humanas.

\section{Considerações finais}

O retorno do feiticismo do crescimento à região europeia, correspondendo a uma nova aposta no produtivismo e na melhoria dos indicadores econômicos, encerra um perigo para a educação e o desenvolvimento, pois, como vimos, pode arregimentar a educação a uma visão excessivamente reducionista do desenvolvimento, de baixa intensidade em preocupações ambientais e não levando em linha de conta as aspirações das pessoas.

Importa dizer, nestas considerações finais, que a resolução das crises do emprego e das dívidas soberanas, seja no contexto europeu ou em qualquer outro lugar, não tem que passar pela ressacralização do crescimento a qualquer preço. A procura de sociedades mais justas e a defesa da sustentabilidade ambiental também são boas para o emprego e o controle das dívidas públicas. Não é reduzindo o desenvolvimento à melhoria do produto interno bruto e a educação a uma estratégia de submissão aos seus desígnios que avançaremos para uma sociedade mais equitativa em termos de oportunidades básicas e também mais respeitadora das condições ecológicas à sua sobrevivência.

A eventualidade de uma regressão a discursos minimalistas de educação e desenvolvimento torna atual a necessidade 
da sua ressignificação através da reafirmação da centralidade das vidas das pessoas nas perspetivas futuras de educação e desenvolvimento. O que importa é a vida das pessoas e o respeito pela dignidade de todas. Ora, isso só é possível numa nova narrativa de educação e desenvolvimento que não deixe de fora ninguém no seu desenho e na sua materialização, designadamente as organizações da sociedade civil que, em múltiplos fóruns e no dia a dia, implicam educação para um desenvolvimento sustentável e verdadeiramente humano, porquanto, focalizado nos valores e nas aspirações de mais justiça, liberdade, respeito, reconhecimento, democracia e participação na condução e gestão daquilo que a todos é politicamente comum.

A sociedade civil, mesmo a mais inovadora e reivindicativa, não garante, por si só, a ressignificação da educação e do desenvolvimento nesse sentido, pois essa tarefa, sem a força impulsionadora da entidade estatal, não irá muito longe. É preciso contar com o Estado com o seu poder regulador, tanto na educação quanto no desenvolvimento. E se se der o caso, como na região europeia, em que os poderes públicos vivem demasiado absorvidos com as agendas do crescimento, importa conquistá-los para a ressignificação da educação e do desenvolvimento através do protesto e da apresentação de propostas, como aliás é da tradição das organizações da sociedade civil que interpelam o status quo e abrem fissuras nas mentalidades mais firmemente estabelecidas (HABERMAS, 2012, p. 163).

Uma vez que a política da sociedade civil, como sublinha Walzer (2008, p. 121), "é necessariamente experimental", nada mais resta, nas presentes circunstâncias, que ensaiar, desde as suas esferas, os primeiros passos de uma ressignificação que se coloca na linha da frente contra a eventual degradação da educação e do desenvolvimento numa gramática da exploração dos recursos ambientais e humanos em função do produtivismo e da melhoria dos indicadores que hoje sobressaem no discurso político mais economicista. 


\section{Referências}

BAUDRILLARD, Jean. La société de consommation. Paris: Denoël, 1970.

BAUMAN, Zygmunt. Confiança e medo na cidade. Rio de Janeiro: Zahar, 2009.

COMISSÃO EUROPEIA. Governança europeia. Um livro branco. Bruxelas: Comissão Europeia, 2001.

. Estratégia Europa 2020. Bruxelas: Comissão Europeia,

2010.

CORTINA, Adela. Hasta un pueblo de demónios. Ética pública y sociedad. Madrid: Taurus, 1998.

DOBSON, Andrew. Ciudadanía y medio ambiente. Barcelona: Proteus, 2010.

HABERMAS, Jürgen. Um ensaio sobre a constituição da Europa. Lisboa: Edições 70, 2012.

KEANE, John. A sociedade civil. Lisboa: Temas e Debates, 2001.

LATOUCHE, Serge. La voie de la décroissance. Pour une société d'abondance frugal. In: CAILLÉ, Alain; HUMBERT, Marc; LATOUCHE, Serge; VIVERET, Patrick (Eds.). De la convivialité. Dialogues sur la société conviviale à venir. Paris: La Découverte, p. 43-72, 2011. LAVAL, Christian; VERGNE, Francis; CLÉMENT, Pierre; DREUX, Guy. La nouvelle école capitaliste. Paris: La Découverte, 2011.

LAVILLE, Jean-Louis. Politique de l'association. Paris: Seuil, 2010. LIMÓN, Dolores. Ecociudadanía: participamos en democracia con un compromiso ético ambiental. In: BOLÍVAR, Antonio y GUARRO, Amador (Coords.). Educación y cultura democráticas. Madrid: Wolters Kluwer, p. 94-115, 2007.

NUSSBAUM, Martha. Crear capacidades. Propuesta para el desarrollo humano. Barcelona: Paidós, 2012.

OCDE. Le développement participative et la bonne gestion des affaires publiques. Paris: Ocde, 1995.

OLVERA, Alberto (Coord.). Sociedad civil, esfera pública y democratización en América Latina. México: Fondo de Cultura Económica y Universidad Veracruzana, 2003.

OTAYEK, René. A descentralização como modo de redefinição do poder autoritário? Algumas reflexões a partir de realidades africanas. Revista Crítica de Ciências Sociais, n.77, p. 131-150, 2007.

PASCUAL ESTEVE, Josep. El papel de la ciudadanía en el auge y decadencia de las ciudades. El fin del gerencialismo o la recuperación 258 - Universidade Católica de Pernambuco 
de lo publico y sus actores. Valencia: Tirant lo Blanch, 2011.

PEDRAJAS, Marta y JORDAN, Josep. Políticas en pro de un desarrollo humano. In: CORTINA, Adela y PEREIRA, Gustavo (Eds.). Pobreza y libertad. Erradicar la pobreza desde el enfoque de Amartya Sen. Madrid: Tecnos, p. 211-234, 2009.

PÉREZ-DÍAS, Víctor. El malestar de la democracia. Barcelona: Crítica, 2008.

PIROTTE, Gautier. La notion de société civile. Paris: La Découverte, 2007.

PNUD. Relatório do desenvolvimento humano. Lisboa: Mensagem, 2003.

REQUENA, Félix. Redes sociales y sociedad civil. Madrid: Centro de Investigaciones Sociológicas, 2008.

ROSANVALLON, Pierre. La société des égaux. Paris: Seuil, 2011.

SEN, Amartya. A educação como desenvolvimento. Lisboa: Gradiva, 2003.

. Temas claves del siglo XXI. In: SEN, Amartya y KLIKS-

BERG, Bernardo (Eds.). Primero la gente. Una mirada desde la ética del desarrollo a los principales problemas del mundo desarrollado. Barcelona: Deusto, p. 13-117, 2007.

TEJERINA, Benjamin. Movimientos sociales, espacio publico y ciudadanía. Los caminos de la utopía. Revista Crítica de Ciências Sociais, n.72, p. 67-97, 2005.

UNESCO. Década das Nações Unidas da Educação para o Desenvolvimento Sustentável: Documento Final. Brasília: Unesco, 2005.

WALZER, Michael. The concept of civil society. In: WALZER, Michael (Ed.). Toward a global civil society. Providence/Oxford: Berghahn, 1998, p. 7-27.

. Política e paixão. Rumo a um liberalismo mais igualitário.

São Paulo: WMF Martins, 2008.

. Pensar politicamente. Barcelona: Paidós, 2010.

WARREN, Mark. Que tipo de sociedade civil é melhor para a democracia? In: VIEGAS, José; PINTO, António; FARIA, Sérgio (Orgs.). Democracia: novos desafios e novos horizontes. Lisboa: Celta, p. 8597, 2004.

\section{Endereço do autor:}

e-mail: mbarbosa@ie.uminho.pt 